\title{
The use of morbidity questionnaires to identify communities with high prevalences of schistosome or geohelminth infections in Tanzania
}

\author{
M. Booth ${ }^{\star}$, C. Mayombana ${ }^{2}$, H. Machibya ${ }^{3}$, H. Masanja ${ }^{2}$, P. Odermatt1,2, J. Utzinger1,2 and P. Kilima \\ 1 Department of Public Health and Epidemiology, Swiss Tropical Institute, Socinstrasse 57, CH 4051 Basel, Switzerland; \\ 2Ifakara Health Research and Development Centre, PO. Box 53, Ifakara, Tanzania; ${ }^{3}$ District Health Office, Morogoro Rural \\ District, Morogoro, Tanzania; 4Ministry of Health, Dar es Salaam, Tanzania
}

\begin{abstract}
Parasitic infections were investigated in Morogoro Rural District, Tanzania, between October 1992 and June 1993. A total of 4589 schoolchildren (aged 7-17 years) from 30 primary schools was screened for infection with Ascaris lumbricoides, Trichuris trichiura, hookworms (3456 children only), Schistosoma mansoni and $S$. haematobium. The children were also asked about their recent experiences of the following: diarrhoea, abdominal pain, blood in stool, perception of suffering from schistosomiasis, and worm infection and examined for spleen and liver enlargement. Among schools, there were correlations between the prevalence of $S$. mansoni infection and bloody stools, spleen enlargement and liver enlargement, and between $S$. haematobium infection and the presence of blood in urine. To exclude ecological explanations for the correlations, logistic regression was used to estimate the adjusted odds ratio (OR) for each infection and each sign or symptom. No sign or symptom was significantly associated with any geohelminth infection. Reported blood in stool was significantly associated with $S$. mansoni infection ( $\mathrm{OR}=1 \cdot 62, P=0 \cdot 045$ ). Reported blood in urine was significantly associated with $S$. haematobium infection ( $\mathrm{OR}=7 \cdot 71, P<0 \cdot 001$ ), as was reported blood in stool $(\mathrm{OR}=11.52, P<0.001)$, indicating that presence of blood in either form of excreta was related to the local term for schistosomiasis. These results support the possibility of using reported blood in stool as a means of rapid assessment for identifying communities with a high prevalence of $S$. mansoni infection.
\end{abstract}

Keywords: geohelminthiasis, schistosomiasis, Ascaris humbricoides, Trichuris trichiura, hookworms, Schistosoma haematobium, Schistosoma mansoni, prevalence assessment, morbidity, questionnaire, children, Tanzania

\section{Introduction}

Conventional approaches to identifying communities with high prevalence of parasitic infection are usually too expensive and time-consuming for countries such as Tanzania. Some workers have therefore investigated alternative approaches using questionnaires. A series of studies in a rural Tanzanian district identificd villages with high prevalences of Schistosoma haematobium infection using a simple questionnaire, a cost-effective screening technique (LENGELER et al., 1991a, 1991b, 1991c). The approach was validated in 7 other African countries (RUSG, 1995) before being recommended by the World Hcalth Organization (WHO) as a method of screening communities for $S$. haematobium infection by District health management teams (CHITSULO et al., 1995).

The morbidity questionnaire approach has also been applied to $S$. mansoni infection, but primarily to aid diagnosis at the individual level. Together with clinical studies, various morbidity indicators have been significantly associated with infection, including diarrhoea, hepatomegaly, splenomegaly, and reported blood in stool (ONGOM \& BRADLEY, 1972; SUKWA et al., 1985; GRYSEELS \& POLDERMAN, 1987; GRYSEELS, 1988; Proletti \& ANTUNES, 1989; Lima E Costa et al., 1991). More recently, attributable risk analysis has been applied to data from Burundi and China, where a high fraction of bloody stool episodes could be attributed to $S$. mansoni and $S$. japonicum infection (GUYATT et al., 1995; BoOTH et al., 1996). Together, these observations suggest that development of rapid assessment indicators for intestinal schistosomiasis is feasible.

In the present paper we describe the results of the first large scale investigation of this method of assessing infections with $S$. mansoni, S. haematobium, Ascaris lumbricoides, Trichuris trichiura and hookworms. We describe the age-related distribution of helminth infections and several signs and symptoms among children in Morogoro Rural District, Tanzania and report on the potential of the questionnaire-based approach in the identification of communities with high prevalence of each helminth infection, using logistic regression meth-

*Author for correspondence; phone +41612848427 , fax +41 612717951 , e-mail booth@ubaclu.unibas.ch ods to ensure that any observed gcographical corrclations were not ecological.

\section{Materials and Methods \\ Sttudy area}

The study was conducted in 30 villages of Morogoro Rural District between October and December 1992. The district is one of the 5 that form Morogoro Region and lies $500-1000 \mathrm{~m}$ above sea level, covers an area of $19250 \mathrm{~km}^{2}$, and contains the Uluguru mountains. To the north, the average rainfall is approximately 1500 $\mathrm{mm}$ per annum. In the south of the district, which includes the mountainous area, annual rainfall ranges from $2000 \mathrm{~mm}$ to $2500 \mathrm{~mm}$. The short rainy season occurs between late October and mid January, and the long rainy season between March and May. Minimum and maximum daily temperatures in the study area are $10-21^{\circ} \mathrm{C}$ and $26-34^{\circ} \mathrm{C}$ respectively.

\section{Sampling schools}

A list of all the schools in the district was obtained from the district education officer. A second list was prepared, excluding schools in the mountains and those which were remote and inaccessible. From this list, 30 schools were selected at random. Meetings at schools and in the adjacent communities were organized before the study, in order to inform parents about the aims of the project and to seek consent. In each school, 160-180 children aged 7-17 years were randomly selected for parasitological and clinical examination. A morbidity questionnaire was also administered, focusing on symptoms commonly associated with intestinal helminths and schistosomiasis with a recall period of 2 months.

\section{Stool examination}

All selected children were given stool containers one night before the survey and asked to collect stool at home the next morning and to bring the filled container to school. At school, the specimens were macroscopically examined for consistency, mucus and overt blood before using the Kato-Katz technique (KATZ et al., 1972). The slides were examined the next day for the presence of S. mansoni. A. lumbricoides or T. trichiura 
eggs. Approximately $75 \%$ of all supplied stools were examined using the saline flotation method (YANG \& SCHOLTEN, 1977) for hookworm eggs. Each stool sample was examined only once.

\section{Urine examination}

Urine specimens were collected between $10: 00$ and 13:00. They were first examined macroscopically for macrohaematuria. With specimens without macrohaematuria, a reagent strip test to identify microhaematuria was performed, followed by filtration of $10 \mathrm{~mL}$ of urine using a Nuclepore ${ }^{\mathrm{TM}}$ membrane as described by ZUMSTEIN (1983). The filter was examined under the microscope and any eggs of $S$. haematobium were counted.

\section{Morbidity questionnaire}

A questionnaire was first tested and then administered in the common language (Kiswahili) by 2 clinical officers, who were not aware of the parasitological and clinical findings. Children were asked to recall episudes of bloody diarrhoea, bloody urine, diarrhoea, bloody stools and abdominal pain in the 2 months before the survey. They were also asked if they thought they currently had worms or schistosomiasis (minyoo and kichocho, respectively, in Kiswahili).

\section{Glinical examination}

Schoolchildren were examined for liver and spleen enlargement by 2 clinical workers who were unaware of the findings of the other surveys. When the liver was palpable, the maximum size was measured in centimetres from the right costal margin in the mid-clavicular line whilst the child was supine. Children were palpated while standing for spleen enlargement and the size was measured using the classification of HACKETT (1944).

\section{Data analysis}

Prevalences of each infection, sign and symptom were estimated for each age group and each school population. Confidence limits $(95 \%)$ for the morbidity indicators were estimated as described by FLEISS (1981). For each infection, the prevalence and arithmetic mean intensity (number of eggs per gram of faeces or $10 \mathrm{~mL}$ of urine) were estimated for each age group and sex. The relationship between the prevalence of morbidity and the prevalence of infection was also assessed for each sign, symptom and parasite species, using the rank correlation test of KENDALL (1938) to test for any geographical correlation between each infection and morbidity indicator.

Logistic regression was used to identify which of the significant rank correlations were least likely to be ecological, by testing for associations between individual signs and the presence of particular infections having adjusted for sampling in different schools. This analysis was conducted using the Egret ${ }^{\mathrm{TM}}$ computer program (SERC, 1991). Models were constructed with a single sign or symptom as the dependent variable, and terms for one or more infections, sex and age (Table 3). The school of each child was added as a random effect, in order to adjust for random variation in the prevalence of each sign or symptom among the schools. Since hookworm data were available for only $75 \%$ of the children, each model was fitted on a reduced dataset with a term for hookworm infection, and then on the whole dataset without the term for hookworm infection. From the output of each model, the adjusted odds ratio (OR) for each infection and associated value of $P$ (null hypothesis: $\mathrm{OR}=1$ ) were recorded.

\section{Results}

A total of 4589 children from 30 schools entered the surveys, although not all children provided information for all surveys; only 3456 could be examined for hookworm infection. The most common infection was $S$. haematobium, with an overall infection prevalence of

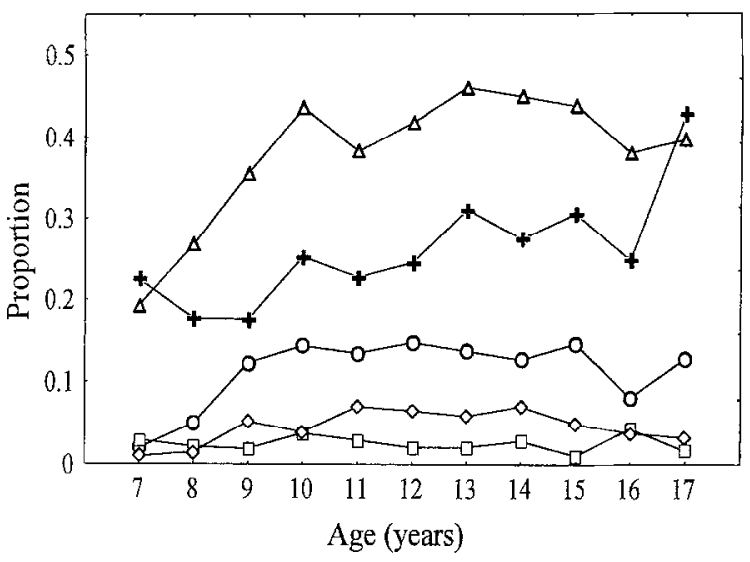

Fig. 1. Relationship between infection prevalence and age for 5 helminth infections recorded in children aged between 7 and 17 years of age in Morogoro Rural District, Tanzania. $\triangle, S$ haematobium; +, hookworms; $O, A$. lambricoides; $\diamond, S$. mansoni; $\square$, T. trichiura.
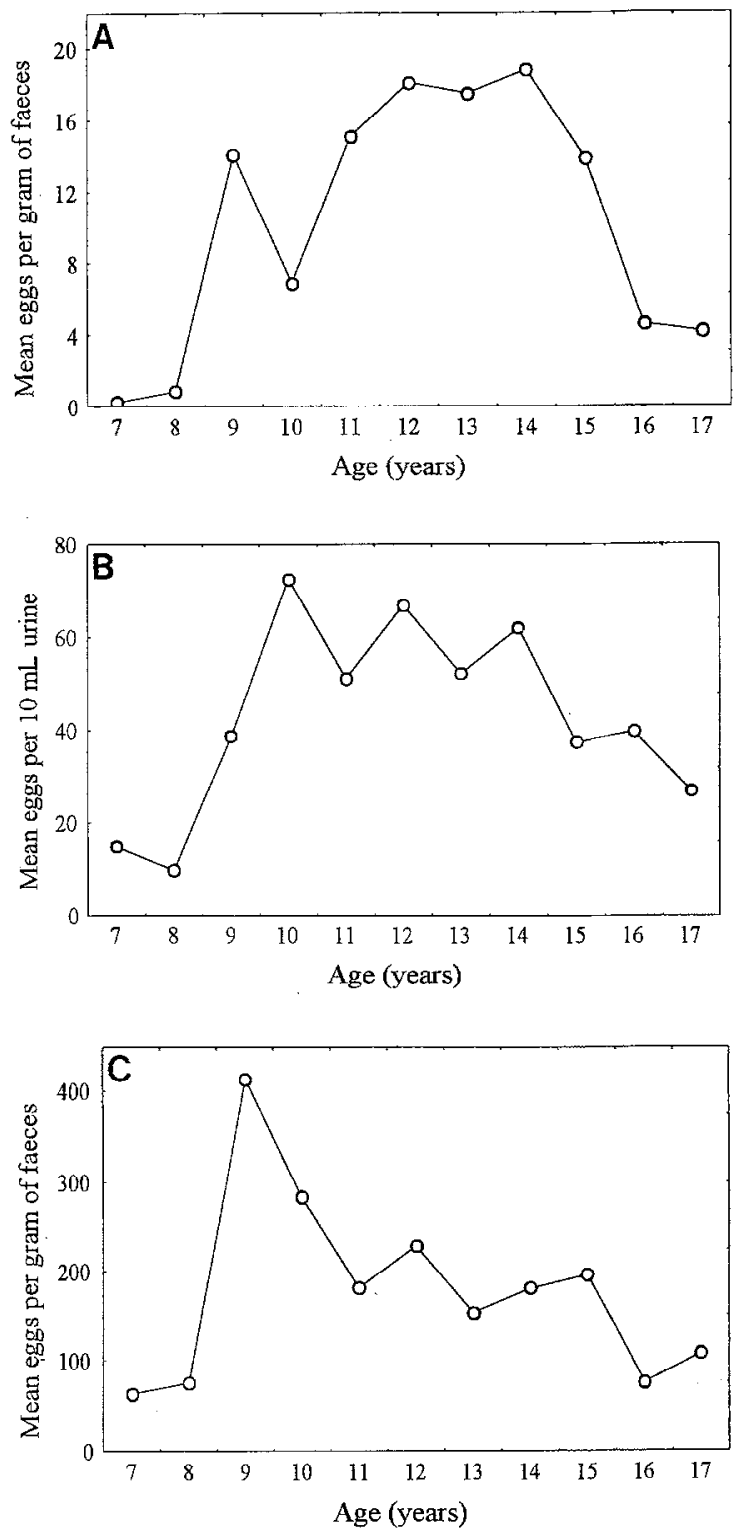

Fig. 2. Relationships between age and mean egg counts of (A) $S$. mansoni, (B) $S$. haematobium, and (C) A. lumbricoides recorded in children in Morogoro Rural District, Tanzania. 
$39 \cdot 6 \%$ (range $6 \cdot 5-90 \cdot 4 \%$ by school). The overall prevalence of $S$. mansoni infection was low $(6 \cdot 4 \%)$, but among schools it was highly heterogeneous in 2 schools the infection prevalence reached $54.7 \%$ and $81.0 \%$, respectively. The most common geohelminth infection was hookworm, with an overall infection prevalence of $26.3 \%$ (range $1.6-51.9 \%$ ). Among the other infections, $13.9 \%$ of the children were infected with $A$. lumbricoides (range $0-78.0 \%$ ), and $2.3 \%$ were infected with $T$. trichiura (range $0-9 \cdot 2 \%$ ).

Age-prevalence and age-intensity profiles are shown in Figs 1 and 2, respectively. The prevalence of hookworm infection increased continually with age, whereas $S$. haematobium infection prevalence rcachcd a pcak in the 13 years old age group. The less common infections showed little variation in infection prevalence with age; nonethcless, infection intensities were highly variable. Both $S$. mansoni and $S$. haematobium egg counts were highest in the 9-14 years age range, and mean $A$. lumbricoides infection intensity reached a peak in the 9 years old age group before rapidly declining (Fig. 2).

Overall prevalences of each recorded sign and symptom are given in Table 1 . Perceived infection with schistosomiasis was reported by over $30 \%$ of all schoolchildren, and was the most common indicator. The most common sign was spleen enlargement, and the most common reported symptom was blood in urine. The prevalence of reported bloody diarrhoea was very low, and this morbidity indicator was therefore excluded from further analysis. The prevalence of spleen enlargement varied most widely with age, peaking in the 9 years old children and rapidly falling thereafter (Fig. 3). Reported blood in urine and perceived schistosomiasis had very similar age-prevalence profiles, which corresponded closely with that for $S$. haematohium infection (Fig. 2). The prevalence of reported diarrhoea also reached a peak in 9 years old children, and the gastro-intestinal symptoms were generally less prevalent in older children.

Table 1. Overall prevalences of nine morbidity indicators measured during surveys of children from Morogoro Rural District, Tanzania

\begin{tabular}{lc}
\hline Indicator & Prevalence $(\%)$ \\
\hline Bloody stool & $4 \cdot 46(3 \cdot 78-5 \cdot 24)$ \\
Blood in urine & $28 \cdot 73(27 \cdot 18-30 \cdot 32)$ \\
Bloody diarrhoea & $1 \cdot 54(1 \cdot 16-2 \cdot 04)$ \\
Abdorninal pain & $4 \cdot 06(3 \cdot 42-4 \cdot 81)$ \\
Diarrhoea & $23 \cdot 75(22 \cdot 30-25 \cdot 26)$ \\
Enlarged liver & $5 \cdot 29(4 \cdot 55-6 \cdot 12)$ \\
Enlarged spleen & $28 \cdot 02(26 \cdot 49-29 \cdot 60)$ \\
Perceived worm infection & $10 \cdot 54(9 \cdot 51-11 \cdot 66)$ \\
Perceived schistosomiasis & $31 \cdot 14(29 \cdot 54-32 \cdot 75)$ \\
\hline
\end{tabular}

aPercentages reporting symptom or fulfilling case definition for liver or spleen enlargement (see text); $95 \%$ confidence intervals are given in parentheses.

\section{Rank correlation analysis}

Prevalence relationships between morbidity indicators and helminth infection were assessed by rank correlation (Table 2). $S$. haematobium infection prevalence was highly correlated with the prevalence of perceived schistosomiasis and with the prevalence of reported blood in urine. Also significant were the correlations betwecn the prevalence of $S$. mansoni infection and reported bloody stool, liver enlargement, perceived worm infection, reported abdominal pain and spleen enlargement. There was no significant relationship between the prevalence of $A$. lumbricoides and any sign or symptom, and the apparent negative correlations between hookworm infection prevalence and the prevalence of several signs and symptoms could be explained by the highly significant negative correlation which was found between the prevalence of hookworm and $S$. mansoni in-
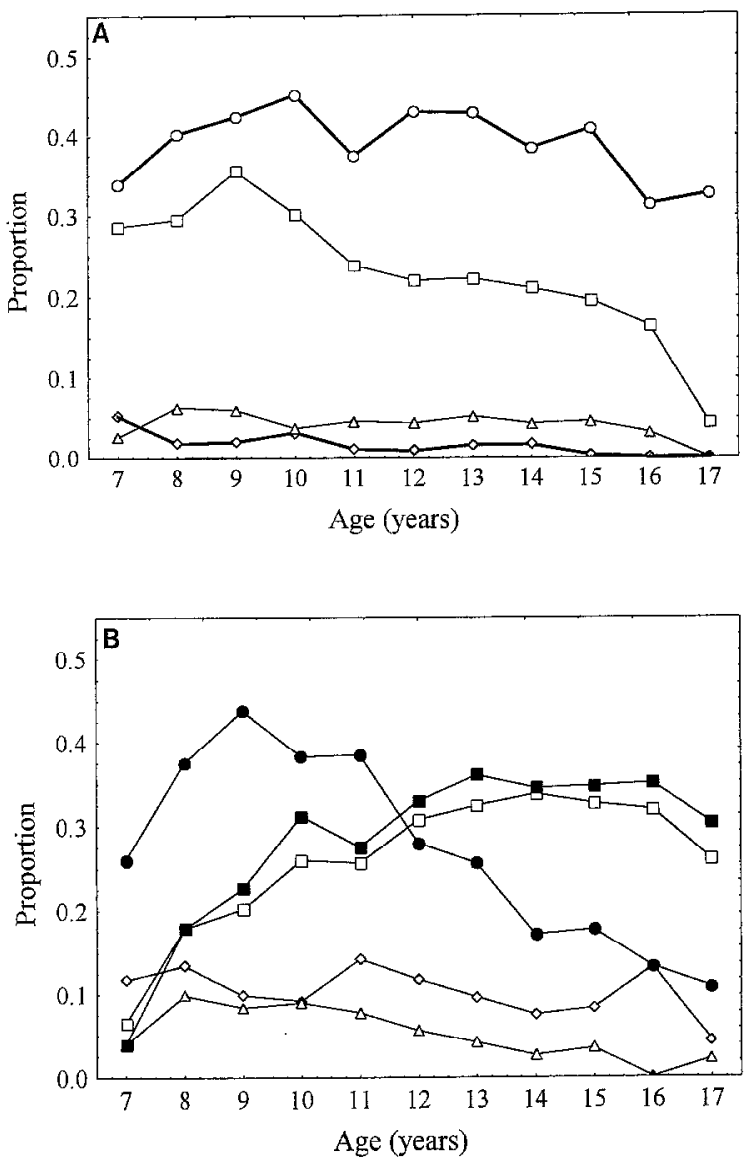

Fig. 3. Relationships between age and prevalence of (A) reported gastro-intestinal symptoms $(O$, abdominal pain; $\square$, diarrhoea; $\diamond$, bloody diarrhoea; $\Delta$, bloody stool) and (B) other morbidity indicators $(\square$, bloody urine; $\diamond$, perceived worm infection; $\square$, perceived schistosomiasis infection; $\triangle$, liver enlargcment; , splecn cnlargement).

Table 2. Kendall's rank correlation analysis of the prevalences of four helminth infections and eight morbidity indicators in schoolchildren in Morogoro Rural District, Tanzania

\begin{tabular}{|c|c|c|c|c|c|c|c|c|}
\hline & \multicolumn{2}{|c|}{ A. lumbricoides } & \multicolumn{2}{|c|}{ S. haematobium } & \multicolumn{2}{|c|}{ Hookworms } & \multicolumn{2}{|c|}{ S. mansoni } \\
\hline & $\tau$ & $P$ & $\tau$ & $P$ & $\tau$ & $P$ & $\tau$ & $P$ \\
\hline Bloody stool & $0 \cdot 152$ & $0 \cdot 2560$ & 0.105 & $0 \cdot 4305$ & -0.430 & 0.0013 & $0 \cdot 488$ & 0.0003 \\
\hline Blood in urine & -0.028 & 0.8305 & $0 \cdot 801$ & $<0.001$ & $0 \cdot 058$ & 0.6630 & 0.066 & $0 \cdot 6243$ \\
\hline Diarrhoea & -0.008 & 0.9488 & $0 \cdot 320$ & 0.0167 & $-0 \cdot 289$ & 0.0311 & $0 \cdot 249$ & 0.0624 \\
\hline Abdominal pain & $-0 \cdot 020$ & $0 \cdot 8810$ & 0.246 & $0 \cdot 0658$ & $-0 \cdot 368$ & $0 \cdot 0060$ & 0.343 & 0.0104 \\
\hline Liver enlargement & $0 \cdot 219$ & $0 \cdot 1014$ & $0 \cdot 159$ & $0 \cdot 2330$ & $-0 \cdot 398$ & 0.0030 & $0 \cdot 488$ & $0 \cdot 0003$ \\
\hline Spleen enlargement & $0 \cdot 042$ & $0 \cdot 7485$ & 0.294 & 0.0281 & $-0 \cdot 167$ & $0 \cdot 2127$ & $0 \cdot 412$ & 0.0021 \\
\hline Perceived worm infection & 0.020 & $0 \cdot 8788$ & 0.057 & 0.6720 & $-0 \cdot 413$ & $0 \cdot 0020$ & $0 \cdot 426$ & 0.0015 \\
\hline Perceived schistosomiasis & NA & NA & 0.827 & $<0.001$ & NA & NA & $0 \cdot 109$ & $0 \cdot 4144$ \\
\hline
\end{tabular}

aNA=not applicable. 
fections at the school level $(n=28$, Kendall's $\tau=0 \cdot 41$, $P=0.0023$ ). The prevalence of $T$. trichiura infection was too low in most schools for this analysis.

The relationship between the prevalence of $S$. manso$n i$ infection and reported bloody stool was non-linear
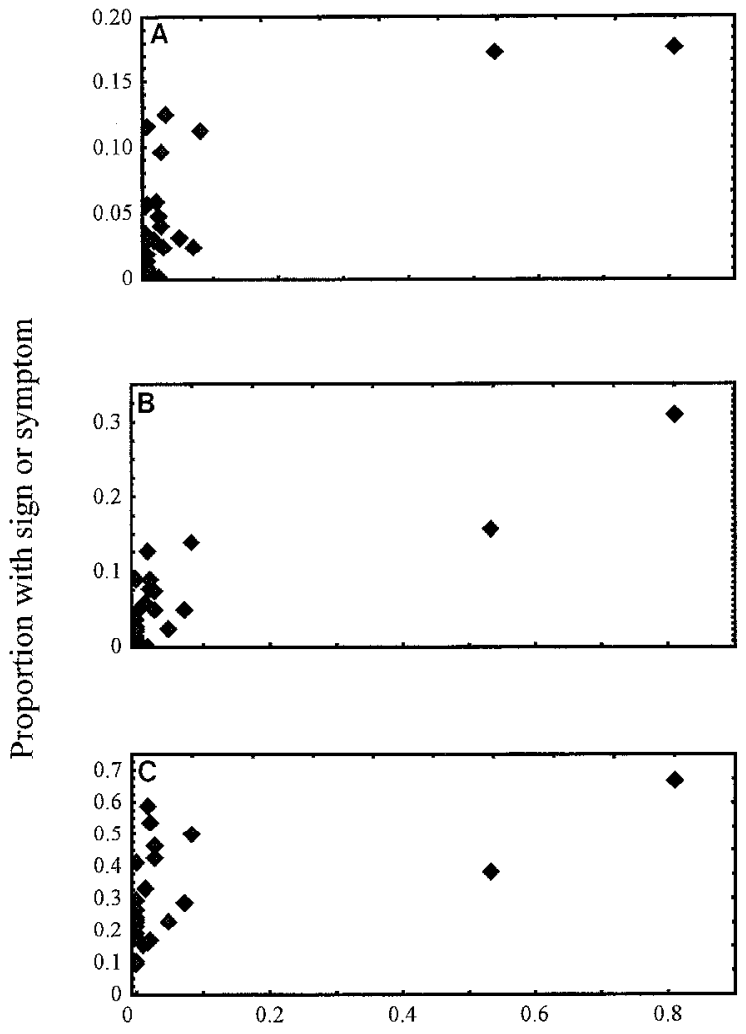

Proportion with S.mansoni infection

Fig. 4. Relationships between the prevalence of S. mansoni infection and the prevalence of $(\mathrm{A})$ reported blood in stool and enlargement of (B) liver and (C) spleen. Each point represents the paired estimates for one school.
(Fig. 4, A), although a high prevalence of $S$. mansoni infection was accompanied by a relatively high prevalence of bloody stool. The relationship between $S$. mansoni infection prevalence and that of liver enlargement was more linear although, like reported bloody stool, there was wide variation in the prevalence of the morbidity indicator at low $S$. mansoni infection prevalences (Fig. 4, B). The 2 schools with high prevalences of $S$. mansoni infection also had high prevalences of spleen enlargement; however, equally high prevalences of spleen enlargement were found in schools with very low $S$. mansoni infection prevalence (Fig. 4, C).

\section{Logistic regression}

The deviances of 8 models are given in Table 3. Models with deviance values of $P>0.9999$ could not have bcen improved by adding extra explanatory variables. Three models had significant deviances $(P<0.01)$, indicating that unrecorded factors contributed to the variation in the prevalences of spleen enlargement, diarrhoca and abdominal pain among schools. Inclusion of a term for hookworm infection in the models affected some odds ratios, and thus the detailed regression results in Table 4 are given for models which included this term. For $A$. lumbricoides, no adjusted odds ratio differed significantly from 1 . Individuals with $T$. trichiura infection were significantly more likely to report abdominal pain after adjusting for the effects of all other infections, but not when the hookworm effect was excluded from the models (OR=1.576, $P=0.282$ ). The association between S. mansoni and reported blood in stool was just non-significant when the hookworm effect was excluded from the models (OR=1.52, $P=0.056)$, and on the borderline of significance when the hookworm term was included (Table 4). Inclusion of an interaction term between $S$. mansoni infection and age in the bloody stool model revealed that the association between infection and morbidity was stronger in older children (Fig. 5).

Both reported blood in urine and a positive answer to the schistosomiasis question were good indicators of $S$. haematobium infection ( $\mathrm{OR}=7.7$ and 7.9 , respectively) (Table 4). In further analysis, we found that females were less likely to report blood in urine $(\mathrm{OR}=0 \cdot 43$, $P=<0.001)$ or to answer that they had schistosomiasis

Table 3. Details and fitting statistics of eight logistic regression models for five helminth infections in schoolchildren

\begin{tabular}{|c|c|c|c|c|}
\hline Outcome variable & Terms included in modela & d.f. & Deviance & $P$ \\
\hline Bloody stool & age, sex, asc, tri, man, hkw & 3175 & $1018 \cdot 2$ & $>0.999$ \\
\hline Blood in urine & age, sex, man, haem & 4065 & $3419 \cdot 3$ & $>0.999$ \\
\hline Diarrhoea & age, sex, asc, tri, hkw, man, haem & 3170 & $3382 \cdot 8$ & $0 \cdot 006$ \\
\hline Abdominal pain & age, sex, asc, tri, hkw, man, haem & 3169 & $4163 \cdot 9$ & $<0.001$ \\
\hline Liver enlargement & age, sex, asc, tri, hkw, man, haem & 3308 & $1162 \cdot 5$ & $>0.999$ \\
\hline Spleen enlargement & age, sex, asc, tri, khw, man, haem & 3308 & $3551 \cdot 1$ & 0.002 \\
\hline Perceived worm infection & age, sex, asc, tri, hkw, man, haem & 2928 & $1999 \cdot 4$ & $>0.999$ \\
\hline Perceived schistosomiasis & age, sex, man, haem, bloody stool & 4064 & $3448 \cdot 6$ & $>0.999$ \\
\hline
\end{tabular}

aasc $=$ Ascaris lumbricoides, haem $=$ Schistosoma haematobium, hkw $=$ hookworms, $\mathrm{man}=S$. mansoni, tri $=$ Trichuria trichiura .

Table 4. Logistic regression analysis for five helminth infections and eight morbidity indicators in schoolchildren

\begin{tabular}{|c|c|c|c|c|c|c|c|c|c|c|}
\hline \multirow[b]{2}{*}{ Morbidity indicator } & \multicolumn{2}{|c|}{ S. mansoni } & \multicolumn{4}{|c|}{ S. haematobium A. lumbricoides } & \multicolumn{2}{|c|}{ T. trichiura } & \multicolumn{2}{|c|}{ Hookworms } \\
\hline & ORa & $P$ & $\mathrm{OR}^{\mathrm{a}}$ & $P$ & $\mathrm{OR}^{\mathrm{a}}$ & $P$ & ORa & $P$ & $\mathrm{OR}^{\mathrm{a}}$ & $P$ \\
\hline Bloody stoolb & 1.62 & $0 \cdot 045$ & $\mathrm{NA}$ & NA & 1.47 & $0 \cdot 113$ & $0 \cdot 3$ & $0 \cdot 238$ & 0.66 & $0 \cdot 117$ \\
\hline Blood in urineb & 0.64 & 0.023 & $7 \cdot 71$ & $<0.001$ & NA & NA & NA & NA & $\mathrm{NA}$ & NA \\
\hline Abdominal pain & 0.78 & 0.46 & 0.89 & 0.235 & 0.89 & 0.428 & 1.53 & 0.091 & 0.89 & $0 \cdot 186$ \\
\hline Diarrhoea & 0.70 & $0 \cdot 139$ & 0.84 & $0 \cdot 100$ & 0.96 & $0 \cdot 795$ & 0.995 & 0.972 & $0 \cdot 77$ & $0 \cdot 781$ \\
\hline Liver enlargement & $1 \cdot 18$ & $0 \cdot 507$ & $1 \cdot 34$ & $0 \cdot 17$ & $1 \cdot 22$ & $0 \cdot 394$ & $2 \cdot 02$ & 0.135 & $1 \cdot 00$ & 0.991 \\
\hline Spleen enlargement & $1 \cdot 34$ & 0.221 & $1 \cdot 14$ & 0.183 & $1 \cdot 02$ & 0.906 & $0 \cdot 70$ & 0.224 & 0.89 & $0 \cdot 260$ \\
\hline Perceived worms & 0.92 & 0.736 & 0.86 & $0 \cdot 297$ & $0 \cdot 73$ & $0 \cdot 139$ & $1 \cdot 32$ & 0.45 & $0 \cdot 71$ & 0.032 \\
\hline Perceived schistosomiasis ${ }^{b}$ & $0 \cdot 76$ & $0 \cdot 185$ & $7 \cdot 79$ & $<0.001$ & $\mathrm{NA}$ & NA & NA & $\mathrm{NA}$ & $\mathrm{NA}$ & $\mathrm{NA}$ \\
\hline
\end{tabular}

aAdjusted odds ratio

bNA=not applicable. 


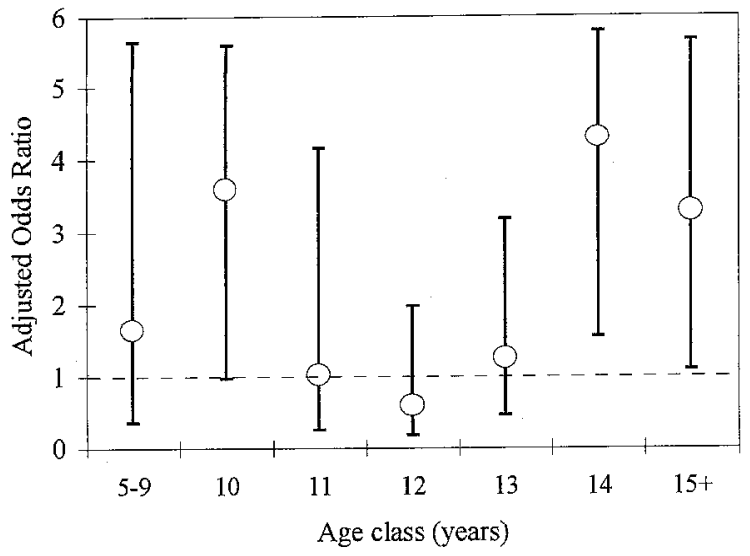

Fig. 5. Relationship between the age and adjusted odds ratio for reported bloody stool and $S$. mansoni infection. Vertical lines indicate $95 \%$ confidence limits; the horizontal broken line indicates which odds ratios were significantly greater than 1 .

(OR=0.64, $P=0.023$ ), even when adjusting for age and infection status in the same model. Finally, we found that children with perceived schistosomiasis were highly likely to have seen blood in their stool $(\mathrm{OR}=11.52$, $P<0.001$ ).

\section{Discussion}

Although schistosomes and geohelminths represent major public health problems in parts of Tanzania, the resources available for their control are very limited. Therefore cost-effective approaches to screening communities for intervention against major parasitic diseases are required. This project attempted to improve the prospects for cost-effective control by focusing on the potential for rapid identification of communities with a high prevalence of helminth infection. Despite the generally low level of infection in the study schools, the analysis has identified which morbidity indicators might be most useful in Morogoro and elsewhere.

Any indicator which is being considered as a rapid assessment tool must be a covariate of the infection of interest. This means that the indicator and infection must not only have the same geographical distribution, but also be closely associated at the individual level to exclude any ecological basis for the geographical correlation. The rank correlation analysis tested the extent of geographical covariation and revealed strong correlations between several infection/outcome combinations, although these were confined to schistosome infections. The strongest correlation was between $S$. haematobium and reported blood in urine, in agreement with previous studies in Tanzania and elsewhere in Africa (LENGELER et al., 1991b; RUSG, 1995). The results of the logistic regression clearly confirmed the association, and thus further supported the use of reported blood in urine as a rapid assessment tool for $S$. haematobium.

There was very little evidence of association between each sign and symptom and the geohelminth infections, in either analysis. The lack of correlation between the prevalence of $A$. lumbricoides infection and the prevalence of any morbidity indicator recorded in the present study effectively precludes the use of gastro-intestinal symptoms as rapid assessment tools for this infection. This does not mean that there was no morbidity attributable to $A$. lumbricoides infection at the time of the surveys, but does suggest the need for alternative methods of directly estimating the public health impact of this species.

Although hookworm infection prevalence was negatively correlated with the prevalence of diarrhoea, blood in stool and liver enlargement, this is likely to have been a result of negative correlations between the prevalence of the true aetiological agents and hookworm infection.
Hookworm infection intensities could not be measured but, with an overall prevalence around $25 \%$, it is unlikcly that many people had infection intensities high enough to cause significant morbidity (LWAMBO et al., 1992). $\Lambda$ s the prevalence and mean intensity of $T$. trichiura infection were low, this infection can also be discounted as a major source of morbidity among schoolchildren from Morogoro.

Significant correlations between the prevalences of $S$. mansoni infection and of reported blood in stool, liver cnlargement and spleen enlargement were found in the rank correlation analysis. The geographical distribution criteria for these indicators to be used as rapid assessment tools were thereby fulfilled. However, in the logistic regression analysis there was only a borderline significant association between $S$. mansoni infection and bloody stool. This association was significant only when hookworms were included in the regression equation, and so its true significance is not clear.

Our confidence in the causal relationship between $S$ mansoni infection and blood in stool is none the less supported by 2 precautions taken in the data collection and analysis. First, a distinction was drawn between bloody diarrhoea and blood mixed with solid faecal matter, thus excluding dysenteric agents as the cause of loss of blood. Second, we adjusted for the potentially biasing effect of other helminth infections. Since both $T$. trichiura and hookworm infections may lead to blood loss in stools (ROCHE \& LAYRISSE, 1966; LAYRISSE et al., 1967), some bloody stool episodes may be attributable to either of these infections in certain communities. Even if the infection intensities of these 2 worms were too low to cause substantial morbidity in Morogoro rural district, hookworm in particular could be a major cause of morbidity in other areas, since the prevalence has been recorded as $60 \%$ and higher in some studies in the adjacent district of Kilombero (TANNER et al., 1991). Thus a high prevalence of bloody stools in soime areas may be attributable to helminth infections other than S. mansoni.

As competing causes can be largely excluded from the present analysis, a parsimonious explanation is required for the observation that only a small number of $S$. mansoni cases reported bloody stools. Such an explanation can be found by considering the influence of fluctuations in schistosome egg excretion, which can be extreme from day to day (ENGELS et al., 1996). Since on most days a small number of eggs is excreted, sampling only once can easily lead to a large number of false negative results (DE VLAS \& GRYSEELS 1993). This means that recall of bloody stool episodes by an infected individual does not guarantee that parasite eggs will be found in a stool sample from the same person. Applying this logic to the present study explains fully why few individuals both reported bloody stool episodes and were correctly diagnosed for infection.

Evidence that a clearer association between reported blood in stool and $S$. mansoni infection could be exploited arose from the logistic regression analysis. An answer of 'yes' to the question 'do you have schistosomiasis?', was very closely associated with the reported presence of blood in stool, as well as with the reported presence of blood in urine. This means that children were likely to have answered 'yes' to the schistosomiasis question if they had observed blood in either their stool or urine. Since the reported presence of blood in urine was not related to the reported presence of blood in stool, we can exclude any ecological basis for this observation. Whether the children recognized that blood in excreta is the result of an infection, or whether they were interpreting the Kiswahili word kichocho to mean the presence of blood in their excreta, cannot be answered from the available data, but clearly warrants further investigation.

We can draw on the results of the present analysis to label several symptoms as unsuitable for further evalua- 
tion in rapid assessment studies of helminth infections, at least in Morogoro. Perception of worm infection, despite a positive prevalence correlation with S. mansoni, was not associated with any helminth species in the regression analysis. This suggests that children were unable to associate any symptom with a local generic term for helminth infection. Reported diarrhoea had a similar odds ratio for all infections, and on this basis alone is unsuitable for diagnosing any one species. Reported abdominal pain is also unsuitable as a rapid assessment tool on this basis.

The prevalence of liver enlargement was strongly correlated with the prevalence of $S$. mansoni infection, but there was no association in the regression analysis. This initially suggests an ecological correlation, but is more likely to have been related to the relative dynamics of $S$. mansoni infection and this form of morbidity (CHAN et al., 1996). None the less, these observations effectively exclude hepatomegaly as a potential rapid assessment tool for $S$. mansoni infection, since the presence of liver enlargement in an individual at the time of a survey may be related more to a history of infection rather than to current infection status, or even to the presence of concurrent infections such as malaria.

Overall, the results of the present analysis suggested that reported blood in stool has the best potential as a symptom-based rapid assessment tool for identifying communities with a high prevalence of $S$. mansoni infection. Further evaluation of this indicator would be worth while, although there will always be a need to account for the potentially biasing effect of other infections and to take into account locel definitions of the term 'blood in stool'. Additional evaluation could also involve assessment in situ of the potential for schistosome transminission, through identification of water bodies likely to contain intermediate snail hosts (ODERMATT, 1994), and questions related to water contact activities (BARRETO, 1993). A 'gold standard' in terms of $S$. mansoni infection is also required, perhaps based on circulating antigens in urine (VAN ETTEN $e t$ al., 1996). With these tools, we can conclude that rapid assessment of communities with a high prevalence of $S$. mansoni infection is a realistic objective for further investigation.

\section{Acknowledgements}

We thank the project team, teachers and students and the authorities in Morogoro, and Professor W. Kilama, the former director of the Tanzanian National Institute of Medical Research (NIMR). Research clearance was obtained from the Medical Research Co-ordination Committee of NIMR through the Tanzanian Commission of Science and Technology. This investigation received financial support from the UNDP/World Bank/WIIO Special Programme for Research and Training in Tropical Diseases (TDR). M.B. was supported by a Wellcome Trust Travelling Fellowship.

\section{References}

Barreto, M. L. (1993). Use of risk factors obtained by questionnaires in the screening for Schistosoma marsomi infection. American Goumal of Tropical Medicine and Hygiene, 48, $742-747$

Booth, M., Guyatt, H. L., Li, Y. \& Tanner, M. (1996). The morbidity attributable to Schistosoma japonicum infection in 3 villages in Dongting Lake region, Hunan Province, China. Tropical Medicine and International Health, 1, 646-654.

Chan, M. S., Guyatt, H. L., Bundy, D. A. P. \& Medley, G. F. (1996). Dynamic models of schistosomiasis morbidity. American foumnal of Tropical Medicine and Hygiene, 55, 52-62.

Chitsulo, L.. Lengeler, C. \& Jenkins, J. (1995). The Schistosomiasis Manual. Geneva: World Health Organization, Methods for Social Research in Tropical Disease, no. 3.

De Vlas, S. J. \& Gryseels, B. (1993). Underestimation of Schistosomiasis mansoni prevalences. Purasitology Today, $\mathbf{8}$ 274-277.

Engels, D., Sinzinkayo, E. \& Gryseels, B. (1996). Day-to-day egg count fluctuation in Schistosama mansoni infection and its operational implications. American fournal of Tropical Medicine and Hygiene, 54, 319-324.
Fleiss, J. L. (1981). Statistical Methods for Rates and Proportions. New York: John Wiley \& Sons.

Gryseels, B. (1988). The morbidity of schistosomiasis mansoni in the Rusizi Plain (Burundi). Transactions of the Royal Society of Tropical Medicine and Hygiene, 82, 582-587.

Gryseels, B. \& Polderman, M. (1987). The morbidity of schistosomiasis mansoni in Maniema (Zaire). Transactions of the Royal Society of Tropical Medicine and Hygiene, 81, 202-209.

Guyatt, H., Gryseels, B., Smith, T. \& Tanner, M. (1995). Assessing the public health importance of Schistosoma mansoni in different endemic areas: attributable fraction estimates as an approach. American foumal of Tropical Medicine and Hygiene, 53, 660-667.

Katz, N., Chaves, A. \& Pellegrino, J. (1972). A simple device for quantitative stool thick smear technique in schistosomiasis mansoni. Revista do Instituto de Medicina Tropical de São Paulo, 14, 397-400.

Kendall, M. G. (1938). A new measure of rank correlation. Biometrika, 30, 81-93.

Layrisse, M., Aparcedo, L., Martinez-Torres, C. \& Roche, M. (1967). Blood loss due to infection with Trichuris trichiura. Amorican Fournal of Tropical Medicine and Hygicne, 16, 613-619.

Lengeler, C., de Savigny, D., Mshinda, H., Mayombana, C., Tayari, S., Hatz, C., Degrémont, A. \& Tanner, M. (1991a) Community based questionnaires and health statistics for the cost-efficient identification of communities at risk for urinary schistosomiasis. International Fournal of Epidemiology, 20, 796-807.

Lengeler, C., Kilima, P., Mshinda, H., Morona, D., Hatz, C. \& Tanner, M. (1991b). Rapid, low-cost, two-step method to screen for urinary schistosomiasis at the district level: the Kilosa experience. Bulletin of the World Health Organization, 69, 179-189.

Lengeler, C., Mshinda, H., de Savigny, D., Kilima, P., Morona, D. \& Tanner, M. (1991c). The value of questionnaires aimed at key informants and distributed through an existing administrative system for rapid and cost-effective health assessment. World Health Quarterly, 44, 150-159.

Lima e Costa, M. M. G., Rocha, R. S., Colley, D., Gazzinelli, G. \& Katz, N. (1991). Validity of selected clinical signs and symptoms in diagnosis of Schistosoma mansoni infection. Revista do Instituto de Medicina Tropical de São Paulo, 33, 12-17.

Lwambo, N. J. S., Bundy, D. A. P. \& Medley, G. F. H. (1992). A new approach to morbidity risk assessment in hookworm endemic communities. Epidemiology and Infection, 108, $469-481$.

Odermatt, P. (1994). Comparative investigation on the population dynamics of Bulinus globosus (Morelet, 1866) and Biomphalaria pfeifferi (Krauss, 1848) (Gastropoda; Planorbidae) with special regard to the assessment of high risk areas for the transmission of intestinal schistosmiasis. PhD thesis, University of Basel.

Ongom, V. L. \& Bradley, D. J. (1972). The epidemiology and consequences of Schistosoma mansoni infection in West Nile, Uganda. I. Ficld studics of a community at Panyagoro. Transactions of the Royal Society of Tropical Medicine and Hygiene, 66, 835-851.

Proietti, F. A. \& Antunes, C. M. F. (1989). Sensitivity, specificity and positive predictive value of selected clinical sign and symptoms associated with schistosomiasis mansoni. In ternational Journal of Epidemiology, 18, 680-683.

Roche, M. \& Layrisse, M. (1966). Nature and causes of hookworm anaemia. American fournal of Tropical Medicine and Hygiene, 15, 1030-1100.

SERC (1991). EGRET: Users Manual. Seattle: Statistics and Epidemiology Research Corporation.

Sukwa, T. Y., Bulsara, M. K. \& Wurapa, F. K. (1985). Evaluation of selected symptoms in the diagnosis of Schistosoma mansoni infection. Tropical and Geographical Medicine, 37 295-297.

Tanner, M., De Savigny, D., Mayombana, C. \& Hatz, C. (1991). Morbidity and mortality at Kilombero, Tanzania, 1982-88. In: Disease and Mortality in Sub-Saharan Africa, Feachem, R. G. \& Jamison, D. T. (editors). Oxford: Oxford University Press, pp. 286-305.

RUSG [The Red Urine Study Group] (1995). Identification of high risk communities for schistosomiasis in Africa: a multicountry study. Geneva: World Health Organization, Social and Economic Research Project Reports, no. 15.

Van Etten, L., Engels, D., Krijger, F. W., Nkulikiyinka, L., Gryseels, B. \& Deelder, A. M. (1996). Fluctuation of schistosome circulating antigen levels in urine of individuals with Schistosoma mansoni infection in Burundi. American foumal of Tropical Medicine and Hygiene, 54, 348-351. 
Yang, J. \& Scholten, T. A. (1977). A fixative for intestinal parasites permitting the use of concentration and permanent staining procedures. American Fournal of Clinical Pathology, $67,300-304$.

Zumstein, A. (1983). A study of some factors infuencing the epidemiology of urinary schistosomiasis at Ifakara (Kilomb- ero District, Morogoro Region, Tanzania). Acta Tropica, 40, $187-204$.

Received 14 April 1997; revised 18 May 1998; accepted for publictaion 19 May 1998

\section{Announcement}

\section{ROYAL SOCIETY OF TROPICAL MEDICINE AND HYGIENE The Transactions}

The Transactions of the Royal Society of Tropical Medicine and Hygiene is issued bi-monthly (six parts per year) and publishes not only papers presented at Society meetings and symposia but also papers and correspondence submitted from all over the world on every aspect of tropical medicine and international health. Supplements on specialist topics are published from time to time.

The Transactions is available to libraries and non-Fellows at an annual subscription of $£ 135.00$. It is dispatched by accelerated surface post at no extra charge.

The annual subscription for Fellows is $£ 50.00$. Applications for Fellowship must be made on the correct form, obtainable from the address below. The rate for bona fide students is $£_{25} 500$.

Further information and application forms for Fellowship can be obtained from:

The Honorary Secretaries

Royal Society of Tropical Medicine and Hygiene

Manson House

26 Portland Place

London, W1N 4EY, UK

Telephone: +44(0)1715802127

Fax: +44 (0) 1714361389

e-mail: mail@rstmh.org
Subscription orders from libraries and non-Fellows should be sent to:

Royal Society of Tropical Medicine and Hygiene Subscription Department

Unit R7, Raglan House

St Peter Street

Maidstone, ME16 OSN, UK

Telephone: $+44(0) 1622756668$

Fax: +44 (0) 1622679774

\section{ROYAL SOCIETY OF TROPICAL MEDICINE AND HYGIENE Garnham Fellowship Fund Appeal}

The appeal for funds to establish fellowships in memory of the late Professor P. C. C. Garnham, FRS, is progressing well. A Garnham Fellowship will enable a young physician or scientist to carry out a short term field project in parasitology or medical entomology in a tropical country of their choice and will be a fitting memorial to Cyril Garnham, who believed passionately in the importance of field work. The appeal has already received generous sponsorship from the Garnham family and the London School of Hygiene and Tropical Medicine. Glaxo Wellcome plc has made a generous donation on the understanding that the Society raises an equivalent amount. Fellows who have not yet contributed but would like to do so are asked to send a donation by cheque (in pounds sterling or Canadian or US dollars) or credit card (stating the number and expiry date) to the Honorary Treasurer, Royal Society of Tropical Medicine and Hygiene, Manson House, 26 Portland Place, London, W1N 4EY, UK; fax +44 (0)1714361389, e-mail mail@rstmh.org

\section{ROYAL SOCIETY OF TROPICAL MEDICINE AND HYGIENE President's Fund}

The aim of the fund is to sponsor prospective Fellows from developing countries, who are at present unable to join because their country's fiscal rules prevent them from paying the subscription.

The fund, known as The President's Fund for Overseas Fellows in Developing Countries, is used to sponsor deserving candidates for full Fellowship of the Society, initially for a period of three years.

The Society relies on donations from Fellows.

Any Fellow willing to donate to the President's Fund in order to help sponsor a deserving Fellow from a developing country is asked to write to Manson House. 